\title{
Male Meiosis and Chromosomal Status in the Genus Lactuca L. from Western Himalayas (India)
}

\author{
Vijay Kumar Singhal, Younas Rasheed Tantray*, Himshikha Gupta, \\ Pawan Kumar Rana, Maninder Kaur and Raghbir Chand Gupta
}

Department of Botany, Punjabi University, Patiala, Punjab-147002, India

Received March 20, 2018; accepted April 26, 2018

\begin{abstract}
Summary Chromosome counts including analyses of male meiosis and pollen fertility have been made on 36 accessions of 10 Lactuca species collected from the western Himalayas. L. orientalis $(2 n=18)$ and L. undulata $(2 n=18)$ have been counted chromosomally for the first time from India and the counts in other species confirmed previous counts. The study also adds the existence of intraspecific diploid cytotype for L. orientalis. B-chromosomes have been reported for the first time in the accession of L. hastata. Cytomixis has been detected in some accessions of $L$. dolicophylla, L. macrorhiza and L. scariola. Consequent to cytomixis, the accessions were depicted some pollen sterility. Based on compiled chromosomal information it is apparent that dysploidy in conjugation with polyploidy seems to play an important role in the evolution of genus the Lactuca seems to be polybasic $(x=5,8,9,17)$, and $x=8$ and $x=9$ seem to be the most common and favored base numbers.
\end{abstract}

Key words Basic number, Chromosome count, Lactuca, Meiotic aberration, Western Himalayas.

The genus Lactuca L. (Tribe Lactuceae, Family Asteraceae) is represented by 147 species of annual, biennial or perennial herbs (Bhellum and Singh 2015). The members are distributed throughout the temperate and warm regions of the world with 16 species in Europe, 12 in America, 43 in Africa and 51 in Asia (Doležalová et al. 2002). Of a total of 25 species reported from India, 16 species are confined to western Himalaya including three endemics viz. L. benthamii, L. kashmiriana and L. pygmaea. Perusal of chromosomal literatures reveals that chromosome numbers are available for only 13 species from India (Gupta and Gill 1983, 1989, Mathew and Mathew 1988, Kaur 2012, Malik 2012, Bala and Gupta 2013, Gupta et al. 2014, 2017, Kaur and Singhal 2015, Rana et al. 2015) and half numbers of the species are not yet to be explored chromosomally. Further review of chromosomal data in species of the world reveals that the Lactuca is quite variable cytologically exhibiting polybasic nature $(x=5,7,8,9,17)$ and intraspecific euploidy. Keeping in view these facts the cytological study have been undertaken to investigate in detail the meiotic cells in 10 Indian species and present an overall picture regarding the role of polyploidy and aneuploidy in the evolution of chromosome number in genus Lactuca.

\section{Materials and methods}

The materials for meiotic observation and pollen fertility were collected from the wild accessions growing in

\footnotetext{
* Corresponding author, e-mail: younasrasheed53@gmail.com DOI: $10.1508 /$ cytologia.83.311
}

the altitudinal range of 1600-3200 m falling under high altitudinal regions of Western Himalayas (Parvati Valley and Solang Valleys in Kullu district and Pangi Valley in the Chamba district in the state of Himachal Pradesh and cold desert regions of Ladakh in the state of Jammu and Kashmir). The exact localities were provided in Table 1. The duly identified and cytologically examined specimens were submitted in the Herbarium maintained by the Department of Botany, Punjabi University, Patiala and accession numbers were obtained (PUN).

For meiotic preparations, unopened capitula of variable sizes were fixed in a freshly prepared Carnoy's fixative (6 parts ethanol, 3 parts chloroform, 1 part acetic acid) for $24 \mathrm{~h}$. Materials were subsequently transferred to $70 \%$ ethanol and stored in a refrigerator. Meiotic preparations were made by squashing the young and developing anthers from ray/disc florets through a standard squash method using 1\% acetocarmine. Chromosome counts were ascertained from the well spread preparations by examining the meiocytes at diakinesis, metaphase I (MI) and anaphase I (A I). Meiocytes were observed carefully at other stages to examine the detailed meiotic course including microsporogenesis. Pollen fertility was estimated through a stainability test for which mature anthers from opened florets were squashed in glycerol and acetocarmine mixture $(1: 1)$. Well filled and fully stained pollen were taken as viable while shriveled and poorly or partially stained were considered as sterile. Photomicrographs of chromosome counts, sporads and pollen grains were taken from the freshly prepared slides using a Leica Qwin digital camera system. 
Table 1. Information on the locality of the collection place with elevation, accession number, gametic chromosome number, ploidy level, pollen fertility and previous chromosome count of investigated Lactuca species from Western Himalayas.

\begin{tabular}{|c|c|c|c|c|c|c|}
\hline Taxon & $\begin{array}{l}\text { Locality along } \\
\text { with elevation }\end{array}$ & $\begin{array}{l}\text { Accession } \\
\text { number } \\
\text { (PUN) }\end{array}$ & $\begin{array}{c}\text { Gametic } \\
\text { chromosome } \\
\text { number }(n)\end{array}$ & $\begin{array}{l}\text { Ploidy } \\
\text { level }\end{array}$ & $\begin{array}{l}\text { Pollen } \\
\text { fertility } \\
\quad(\%)\end{array}$ & $\begin{array}{l}\text { Previous } \\
\text { chromosome } \\
\text { count }(2 n)\end{array}$ \\
\hline \multirow{7}{*}{$\begin{array}{l}\text { L. decipiens Hook. f. \& } \\
\text { Thomson ex C. B. Clarke } \\
\text { L. dissecta } \text { D. Don }\end{array}$} & Panikher, $3020 \mathrm{~m}$ & 61995 & 8 & $2 x$ & 100 & \multirow[t]{2}{*}{16} \\
\hline & Sankoo, $3050 \mathrm{~m}$ & 62006 & 8 & $2 x$ & 100 & \\
\hline & Bembhat, $3080 \mathrm{~m}$ & 61979 & 8 & $2 x$ & 100 & \multirow[t]{5}{*}{16} \\
\hline & $\begin{array}{l}\text { Drass, } 3000 \mathrm{~m} \\
\text { (Parvati Valley) }\end{array}$ & 62133 & 8 & $2 x$ & 100 & \\
\hline & Jari, $1624 \mathrm{~m}$ & 57174 & 8 & $2 x$ & 100 & \\
\hline & $\begin{array}{l}\text { Kasol, } 2614 \mathrm{~m} \\
\text { (Pangi Valley) }\end{array}$ & 57177 & 8 & $2 x$ & 100 & \\
\hline & Muhari, $2600 \mathrm{~m}$ & 58602 & 8 & $2 x$ & 100 & \\
\hline \multirow{7}{*}{$\begin{array}{l}\text { L. dolichophylla Kitam } \\
\quad=\text { L.longifolia } \mathrm{DC} .\end{array}$} & Drass, $3100 \mathrm{~m}$ & 60722 & 8 & $2 x$ & 95 & \multirow[t]{7}{*}{16} \\
\hline & $\begin{array}{l}\text { Mushkoo valley, } 3160 \mathrm{~m} \\
\text { (Parvati Valley) }\end{array}$ & 60723 & 8 & $2 x$ & 100 & \\
\hline & Chhagna, $1700 \mathrm{~m}$ & 58362 & 8 & $2 x$ & 83 & \\
\hline & $\begin{array}{l}\text { Pulga, } 2100 \mathrm{~m} \\
\text { (Pangi Valley) }\end{array}$ & 58401 & 8 & $2 x$ & 91 & \\
\hline & Killar, $2650 \mathrm{~m}$ & 58438 & 8 & $2 x$ & 100 & \\
\hline & Killar, $2560 \mathrm{~m}$ & 58871 & 8 & $2 x$ & 100 & \\
\hline & BRO Office, $2700 \mathrm{~m}$ & 57918 & 8 & $2 x$ & 100 & \\
\hline L. hastata $\mathrm{L}$. & Sankoo, $3100 \mathrm{~m}$ & 60743 & $8+1 B$ & $2 x$ & 100 & 16 \\
\hline \multirow{4}{*}{$\begin{array}{l}\text { L. lessertiana } \\
\qquad \text { (Wall. ex DC.) } \\
\text { Wall. ex C. B. Clarke }\end{array}$} & Panikher, $3010 \mathrm{~m}$ & 60748 & 8 & $2 x$ & 100 & \multirow[t]{4}{*}{16} \\
\hline & Sankoo, $3000 \mathrm{~m}$ & 62127 & 8 & $2 x$ & 100 & \\
\hline & Sankoo, $3050 \mathrm{~m}$ & 62128 & 8 & $2 x$ & 100 & \\
\hline & Sankoo, $3100 \mathrm{~m}$ & 62129 & 8 & $2 x$ & 100 & \\
\hline L.macrorhiza (Royle) & Pandrass, $3200 \mathrm{~m}$ & 60724 & 8 & $2 x$ & 100 & \multirow[t]{7}{*}{16} \\
\hline Hook.f. & Panikher, $3120 \mathrm{~m}$ & 60725 & 8 & $2 x$ & 94 & \\
\hline \multirow[t]{5}{*}{$\begin{array}{l}=\text { Cicerbita macrorhiza } \\
\text { (Royle) Beauv. }\end{array}$} & $\begin{array}{l}\text { Sankoo, } 3000 \mathrm{~m} \\
\text { (Parvati Valley) }\end{array}$ & 62130 & 8 & $2 x$ & 100 & \\
\hline & $\begin{array}{l}\text { Malana, } 2652 \mathrm{~m} \\
\text { (Solang Valley) }\end{array}$ & 58383 & 8 & $2 x$ & 100 & \\
\hline & Palchan, $2400 \mathrm{~m}$ & 59000 & 8 & $2 x$ & 100 & \\
\hline & Palchan, $2400 \mathrm{~m}$ & 59001 & 8 & $2 x$ & 100 & \\
\hline & Dhundhi, $305 \mathrm{~m}$ & 59002 & 8 & $2 x$ & 100 & \\
\hline \multirow[t]{2}{*}{ L.orientalis (Boiss.) Boiss. } & Drass, $3100 \mathrm{~m}$ & 61994 & 9 & $2 x$ & 100 & \multirow[t]{2}{*}{36} \\
\hline & Bembhat, $3000 \mathrm{~m}$ & 62008 & 9 & $2 x$ & 100 & \\
\hline \multirow{6}{*}{$\begin{array}{l}\text { L. scariola L. } \\
\quad=\text { L. serriola (L.) Torn. } \\
\text { L. tatarica (L.) C. A. Mey. }\end{array}$} & Kargil, $2800 \mathrm{~m}$ & 60735 & 9 & $2 x$ & 95 & \multirow[t]{2}{*}{$18,18+0-1 \mathrm{~F}$} \\
\hline & Drass, $3100 \mathrm{~m}$ & 62131 & 9 & $2 x$ & 100 & \\
\hline & Thang, $3120 \mathrm{~m}$ & 60727 & 9 & $2 x$ & 100 & \multirow[t]{4}{*}{$16,18,54$} \\
\hline & $\begin{array}{l}\text { Sankoo, } 3000 \mathrm{~m} \\
\text { (Nubra Valley) }\end{array}$ & 60726 & 9 & $2 x$ & 100 & \\
\hline & $\begin{array}{l}\text { Hundur, } 3010 \mathrm{~m} \\
\text { (Pangi Valley) }\end{array}$ & 62132 & 9 & $2 x$ & 100 & \\
\hline & Sahali, $2600 \mathrm{~m}$ & 58613 & 9 & $2 x$ & 100 & \\
\hline \multirow[t]{2}{*}{ L. undulata Ledeb. } & Kargil, $3000 \mathrm{~m}$ & 61993 & 9 & $2 x$ & 100 & \multirow[t]{2}{*}{18} \\
\hline & Drass, $3100 \mathrm{~m}$ & 62007 & 9 & $2 x$ & 100 & \\
\hline
\end{tabular}

Results

A total of 36 wild accessions representing 10 species of Lactuca collected from various localities falling in the states of Jammu and Kashmir and Himachal Pradesh in North West Himalayas were analyzed and the results of gametic chromosome number, pollen fertility, and detailed meiosis are provided in Table 1. Brief descriptions of meiotic analysis and pollen fertility in each species are given as below.

L. decipiens Hook. f. \& Thomson ex C. B. Clarke: Two accessions from Ladakh division showed eight bivalents at MI (Fig. 1a). A few meiocytes in the accession (PUN 61995) showed two nucleoli of unequal sizes in PMC (Fig. 1b).The meiotic course in the meiocytes including microsporogenesis was noticed to be perfectly normal resulting into equal sized fertile pollen grains.

L. dissecta D. Don: In all the five analyzed accessions PMCs depicted the same gametic chromosome count of $n=8$ as confirmed by the presence of eight bivalents at MI (Fig. 1c).The accessions showed perfectly normal meiosis and $100 \%$ fertile pollen grains (Fig. 1d).

L. dolicophylla Kitam: All the accessions showed the same chromosome number of $n=8$ (Fig. 1e). A few meiocytes in two accessions scored from Mushkoo Valley $(3160 \mathrm{~m})$ and Parvati Valley $(1700 \mathrm{~m})$ showed the phenomenon of cytomixis (Fig. 1f). The meiocytes in these accessions showed some meiotic irregularities involving 


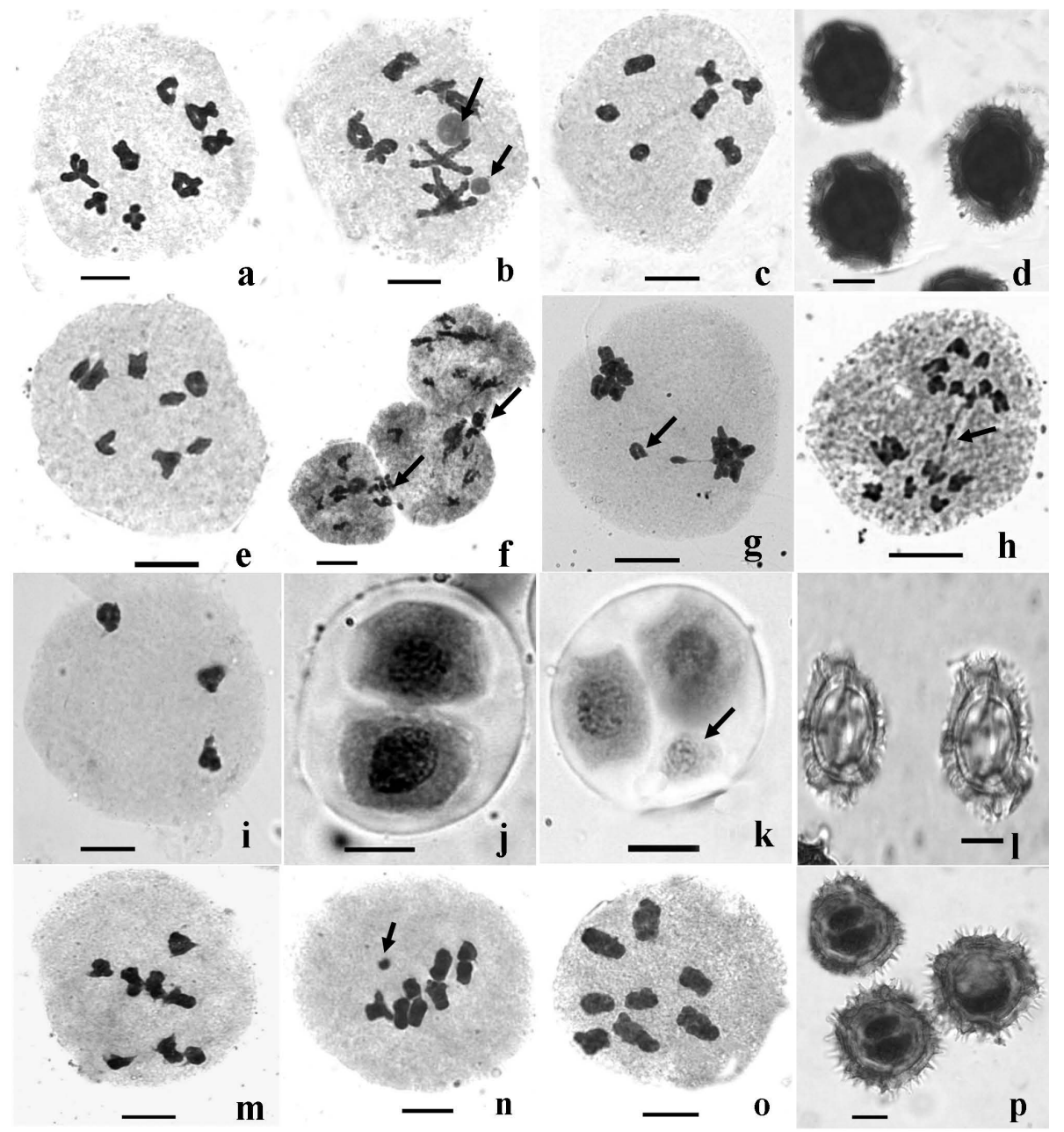

Fig. 1. Male meiosis in Lactuca. L. decipiens: (a) $n=8$ at MI; (b) a PMC showing two irregular sized nucleoli (arrow). L. dissecta: (c) $n=8$ at MI; (d) Stained pollen grains. L. dolicophylla: (e) $n=8$ at MI; (f) three PMCs involved in chromatin transfer (arrow); (g) late disjunction of a bivalent (arrow); (h) chromatin bridge at A I (arrow); (i) tripolar distribution of chromatin; (j) a dyad; (k) triad with micronuclei (arrow); (1) Unstained/sterile pollen grains. L. hastata: (m) $n=8$ at MI; (n) a B-chromosome (arrow). L. lessertiana: (o) $n=8$ at MI; (p) stained pollen grains. Scale bars $=10 \mu \mathrm{m}$.

late disjunction, chromatin bridges and tripolar chromosome distribution (Fig. 1g-i) resulting to abnormal sporads such as dyads and triads (Fig. 1j, k). The products of such sporads yielded $17 \%$ sterile pollen grains (Fig. 11).

L. hastata L.: The wild accession collected from cold deserts of Ladakh (Sankoo, $3100 \mathrm{~m}$ ) showed the gametic chromosome count of $n=8$ which was confirmed from the presence of 8 bivalents at MI (Fig. 1m). A few meiocytes in the accession (PUN 60743) showed the presence of B-chromosome (Fig. 1n). The meiotic course was noticed to be perfectly regular resulting into fertile pollen grains.

L. lessertiana (Wall. ex DC.) Wall. ex C. B. Clarke: All the four accessions showed perfectly normal meiosis with regular eight bivalent formation at MI (Fig. 1o), normal sporads, $100 \%$ fertile and equal sized pollen grains (Fig. 1p).

L. macrorhiza (Royle) Hook. f.: Seven accessions of this species have been studied cytologically for chromosome counts, meiotic course, and pollen fertility. The accessions shared the same chromosome count of $n=8$ and regular meiotic course (Fig. 2a). However, in accession collected from Panikher $(3120 \mathrm{~m}), 14.3 \%$ of the meiocytes showed the phenomenon of cytomixis involving chromatin transfer at different meiotic stages (Fig. 2b). The meiocytes involved in cytomixis also showed disturbances during meiotic course yielding $6 \%$ sterile pollen grains.

L. orientalis (Boiss.) Boiss.: Two accessions showed the presence of nine bivalents at MI (Fig. 2c). Of these, three bivalents are relatively large sized. The meiotic course is perfectly normal resulting into fertile pollen grains (Fig. 2d).

L. scariola L.: Two accessions revealed nine bivalents at diakinesis (Fig. 2e). In one accession collected from Kargil (PUN 60735), a few meiocytes showed cytomixis involving chromatin transfer through cytomictic channels (Fig. 2f). Meiocytes with chromatin bridges were also noticed (Fig. 2g). The accession depicted some pollen sterility $(5 \%)$.

L. tatarica (L.) C. A. Mey.: All the four wild acces- 

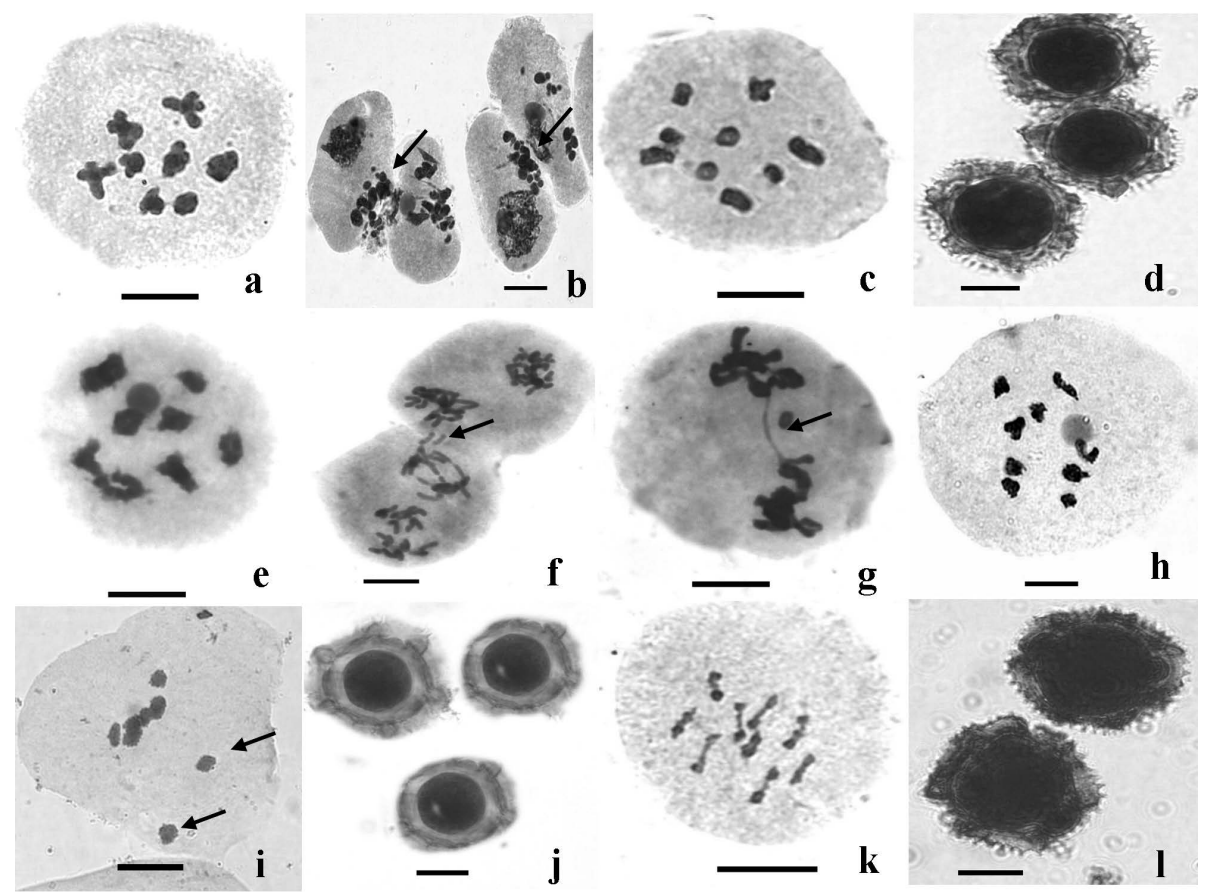

Fig. 2. L. macrorhiza: (a) $n=8$ at MI; (b) PMCs showing chromatin transfer (arrow). L. orientalis: (c) $n=9$ at MI; (d) Stained pollen grains. L. scariola: (e) $n=9$ at Diakinesis; (f) Two PMCs involved in chromatin transfer (arrow); (g) chromatin bridge at T I (arrow). (h) L. tatarica: $n=9$ at diakinesis; (i) a PMC showing out of plate bivalents (arrow); (j) stained pollen grains. L. undulata: (k) $n=9$ at MI; (1) stained pollen grains. Scale bars $=10 \mu \mathrm{m}$.

sions showed nine bivalents at diakinesis (Fig. 2h) and normal meiotic course. However, in one of the accession collected from Nubra valley (PUN 62132) some PMCs showed (Fig. 2i) out of plate bivalents. The accessions showed $100 \%$ fertile pollen grains (Fig. $2 \mathrm{j}$ ).

L. undulata Ledeb.: The detailed meiotic course performed on two accessions showed the presence of nine bivalents at MI (Fig. 2k). The accessions showed regular meiotic course and pollen fertility (Fig. 21).

\section{Discussion}

The present study provides chromosome counts in 10 species of Lactuca from high altitudinal regions and cytologically unexplored regions of Western Himalayas, two of which are the first records from India. Our study also adds a new intraspecific diploid cytotype $(2 n=18)$ for L. orientalis against the earlier report of a tetraploid cytotype $(2 n=36)$ by Babcock et al. (1937) from North America. The present diploid chromosome count of $2 n=18$ for L. undulata is the first chromosome report from India, but confirms the previous reports of $2 n=18$ by Ghaffari (1988) and Nazarova and Ghukasyan (2004) from Iran and Armenia, respectively. The study adds the first record of B-chromosome in L. hastata and confirms the earlier diploid chromosome count of $2 n=16$ from India (Mehra et al. 1965, Shetty 1967, Mathew and Mathew 1988) and North America (Stebbins et al. 1953).

The phenomenon of cytomixis was recorded in three accessions of L. dolicophylla $(n=8)$, L. macrorhiza $(n=8)$ and L. scariola $(n=9)$. The meiocytes in the species also depicted some meiotic aberrations and consequently sterile pollen grains. Such an effect of cytomixis in inducing meiotic irregularities and pollen malformation has already been reported in a number of flowering plants (Mursalimov et al. 2013, Kumar et al. 2014, Gupta et al. 2017). The precise mechanism underlying the phenomenon is currently vague and has acquired various concepts ranging from merely an artifact of cytological preparation (Heslop-Harrison 1966) to a natural process directly under the control of genetic factors (Malallah and Attia 2003). Recently, the researchers have reached to the conclusion that cytomixis is a process of potential evolutionary significance owing to transfer of genetic material between cells destined to form pollen or male gametes (Mursalimov and Deineko 2018)

A compilation of available chromosomal literatures reveals that so far chromosome numbers are known for a total of 87 species $(59.18 \%)$ in the Lactuca. An analysis reveals that $90.66 \%$ species are diploids and $9.33 \%$ species are polyploids, the majority of which are tetraploids. The chromosomally known species depicted several chromosome numbers $(2 n=10,16,18,24,34,54)$. The lowest chromosome number, $2 n=10$ was recorded in $L$. hallaisanesis and L. sagittarioides (Malla et al. 1977, Pak et al. 2001) from Korea and Nepal, respectively. While the highest number of $2 n=54$ was reported in L. tatarica (Stepanov and Muratova 1995) from Russia. Besides, six species depicted the presence of dysploid chromosome variation: $L$. alpine $(2 n=16,18), L$. 


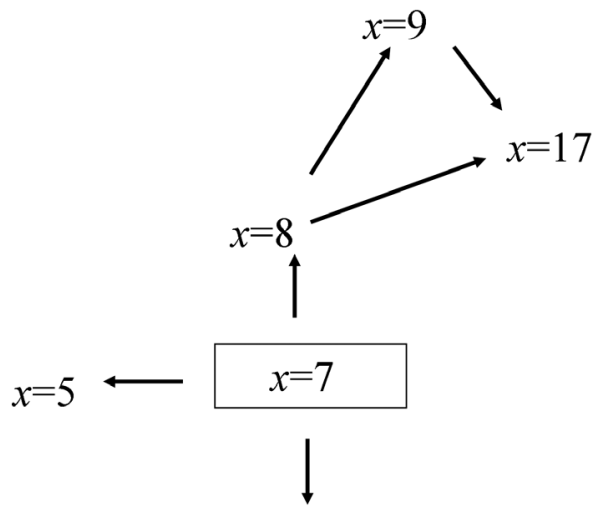

(Ancestral base number of angiosperms)

Fig. 3. Possible origin of basic numbers in Lactuca

bourgaei $(2 n=16,18)$, L. crambifolia $(2 n=16,18), L$. perennis $(2 n=16,18)$, L. picridiformis $(2 n=16,18)$ and L. tatarica $(2 n=16,18)$. The chromosomal variation involving intraspecific euploidy is existent in five species viz. L. capensis $(2 n=16,24)$, L. orientalis $(2 n=18,36), L$. sativa $(2 n=18,36)$, L. sibirica $(2 n=18,36)$ and L. tatarica $(2 n=18,54)$. On the basis of existing chromosomal information, several basic numbers $(x=5,8,9,17)$ for the Lactuca were proposed and suggested it to be polybasic. A great majority of the species are based on $x=9$ (46 species, 52.87\%) and followed by $x=8$ (28 species, $32.18 \%$ ). Only two species of $L$. sagittarioides and $L$. hallaisanensis possessed chromosome numbers in multiple of $x=5$, and five species have chromosome counts in multiple of $x=17$. To pinpoint the probable and favored base numbers for the Lactuca, authors have given due consideration to those haploid numbers which are more prevalent and on which euploid cytotypes are existent as advocated by Kaur et al. (2014) and Rani et al. (2014). Taking into consideration these facts, we are of the opinion that $x=8$ and $x=9$ seem the favored basic numbers for the Lactuca, while $x=5$ and $x=17$ might the derived during the course of evolution (Fig. 3).

\section{Acknowledgements}

Authors wish to thank the University Grants Commission, New Delhi, for providing financial assistance under the DRS, SAP I, II \& III, and ASSIST Programme and awarding Junior Research Fellowship to Younas Rasheed Tantray (Award letter no. 2121430298 12/8/2015). Authors are also thankful to The Head, Department of Botany, Punjabi University, Patiala for providing necessary laboratory, herbarium and library facilities. Thanks are also due to In-charge IPLS-DBT project (BT/PR 4548/INF/22/146/2012) for laboratory facilities.

\section{References}

Babcock, E. B., Stebbins, G. L. Jr. and Jenkins, J. A. 1937. Chromosomes and phylogeny in some genera of the Crepidineae.
Cytologia Fujii Jubilaei: 188-210.

Bala, S. and Gupta, R. C. 2013. Male meiosis and chromosomes numbers in Asteraceaea family from district Kangra of H. P. (Western Himalayas). Int. J. Bot. Res. 3: 43-58.

Bhellum, B. L. and Singh, B. 2015. Taxonomic novelties of the genus Lactuca L. in Jammu and Kashmir (India): diversity, phenology and distribution. Curr. Life Sci. 1: 93-102.

Doležalová, I., Křístková, E., Lebeda, A. and Vinter, V. 2002. Description of morphological characters of wild Lactuca L. spp. genetic resources. HortScience 29: 56-83.

Ghaffari, S. M. 1988. Etudes chromosomiques de quelques phanérogames d'Iran, II. Bull. Soc. Neuchâtel. Sci. Nat. 111: 91-94.

Gupta, H., Gupta, R. C., Kumar, R. and Singhal, V. K. 2017. A profile of chromosome counts, male meiosis and pollen fertility in 45 species of Asteraceae from Parvati Valley in Kullu district, Himachal Pradesh. Caryologia 70: 128-140.

Gupta, R. C. and Gill, B. S. 1983. Cytology of family Compositae of Punjab plains. Proc. Ind. Nat. Sci. Acad. 49B: 359-370.

Gupta, R. C. and Gill, B. S. 1989. Cytopalynology of north and central Indian Compositae. J. Cytol. Genet. 24: 96-105.

Gupta, R. C., Goyal, H., Singh, V. and Goel, R. K. 2014. Meiotic studies in some species of Cichorieae (Asteraceae) from Western Himalayas. Sci. World. J. 2014: 673456.

Heslop-Harrison, J. 1966. Cytoplasmic connections between angiospermic meiocytes. Ann. Bot. 30: 221-234.

Kaur, D. 2012. Cytomorphological Diversity in the Dicotyledonous Plants from Kinnaur District (H. P.). Ph.D. Thesis, Punjabi University, Patiala.

Kaur, H., Mubarak, N., Kumari, S. and Gupta, R. C. 2014. Chromosome numbers and basic chromosome numbers in monocotyledonous genera of the Western Himalayas (India). Acta Biol. Cracov. Ser. Bot. 56: 9-19.

Kaur, M. and Singhal, V. K. 2015. Cytomorphological diversity in some members of family Asteraceae from the ecologically disturbed habitats of Solang valley, Kullu district, Himachal Pradesh. Cytologia 80: 203-222.

Kumar, P., Rana, P. K., Himshikha, Singhal, V. K. and Gupta, R. C. 2014. Cytogeography and pheneomenon of cytomixis in Silene vulgaris from cold regions of northwest Himalayas (India). Plant Syst. Evol. 300: 1477-1486.

Malallah, G. A. and Attia, T. A. 2003. Cytomixis and its possible evolutionary role in the Kuwaiti population of Diplotaxis harra (Brassicaceae). Bot. J. Linn. Soc. 143: 169-175.

Malik, R. A. 2012. Cytomorphological Investigations on some Members of Gamopetalae from Kashmir. Ph.D. Thesis, Punjabi University, Patiala.

Malla, S. B., Bhattarai, S., Gorkhali, M., Saiju, H. and Singh, M. P. 1977. In: Löve, Á (ed.). IOPB chromosome number reports LVII. Taxon 26: 443-452.

Mathew, A. and Mathew, P. M. 1988. Cytological studies on the south Indian Compositae. Glimpses Plant Res. 8: 1-177.

Mehra, P. N., Gill, B. S., Mehta, J. K. and Sidhu, S. S. 1965. Cytological investigations on the Indian Compositae. I. North Indian taxa. Caryologia 18: 35-68.

Mursalimov, S. and Deineko, E. 2018. Cytomixis in plants: facts and doubts. Protoplasma 255: 719-731.

Mursalimov, S. R., Sidorchuk, Y. V. and Deineko, E. V. 2013. New insights into cytomixis: specific cellular features and prevalence in higher plants. Planta 238: 415-423.

Nazarova, E. and Ghukasyan, A. 2004. Chromosome Numbers of Flowering Plants of Armenian Flora. Institute of Botany, National Academy of Sciences RA, Yerevan.

Pak, J. H., Kim, Y. O. and Choi, K. 2001. Taxonomic reconsideration of Lactuca hallaisanensis H. Lév. Korean J. Plant Taxon. 31: 311-319.

Rana, P. K., Kumar, P. and Singhal, V. K. 2015. Chromosome counts, 
chromosomal pairing, and pollen fertility in thirty-eight species of Asteraceae from Pangi Valley in District Chamba of Himachal Pradesh (India). Braz. J. Bot. 38: 837-850.

Rani, S., Jeelani, S. M., Kumar, S., Kumari, S. and Gupta, R. C. 2014. An overview of chromosome and basic numbers diversity in cytologically investigated polypetalous genera from the Western Himalayas (India). Caryologia 67: 1-24.

Shetty, B. V. 1967. In: Löve, Á (ed.). IOPB chromosome number re- ports LVII. Taxon 16: 552-571.

Stebbins, J. L. Jr., Jenkins, J. A. and Walters, M. S. 1953. Chromosomes and phylogeny in Compositae, tribe Cichorieeae. Univ. Calif. Publ. Bot. 26: 401-430.

Stepanov, N. V. and Muratova, E. N. 1995. Chromosome numbers of some taxa of higher plants of Krasnoyarsk territory. Bot. Zhurn. 80: $114-116$. 